\title{
Research on Translation Strategies of Fork Paper-cut Culture in Liupan Mountain Area
}

\author{
Yinping Lv \\ School of Foreign Language \\ Ningxia Normal University \\ Guyuan, China 756000
}

\begin{abstract}
Liupan Mountain paper-cut, a fork art culture, is popular in northwest China, and owns many special features in locality culture, it is welcomed by foreigners in cultural exchange, but translation on paper cut culture isn't in a systematic condition, which isn't good for the spreading of the culture to the world. So, the paper makes a research on paper cuts history and its culture features, explore the translation strategies taken in the fork art culture, fork custom culture and daily life designs, and hopes to enhance the exchange of fork culture in the world and make culture communication easy.
\end{abstract}

Keywords-Chinese-English translation; fork paper-cut culture; translation strategies

\section{INTRODUCTION}

Locating in the northwest of China, Liupan Mountain is also the cradle of the agriculture civilization. People have been living here thousand years ago and shaped the special culture. Fork paper cutting culture is like a blooming flower in the local civilization, which carries the arts' past and present in the land where people living generation after generation. Hard working people express their passions on pieces of refined paper-cuts, reflecting their life and history in the area. Compared to other paper cuts, paper cuts in Liupan Mountain has the clear feature in its culture combined with culture of the Yellow River and Central Plain.

\section{YESTERDAY AND TODAY'S PAPER-CUTS}

Papercut in China can be categorized as two phases, the simple design with the natural features before 1990, at that time, it was widely used in Spring festival, weddings and funeral, every woman can cut it. After 1990, it transformed to the artistic work and stepped into the urban life. The common people who can cut the patterns were becoming less and less. It is regarded as non-intangible heritage culture and person who experts in paper cuts are granted as heritor. Thus, paper cuts culture is divided into two branches, one is for decoration both in rural and urban, and the other is still for fork custom culture.

Traditionally, paper-cuts in Liupan Mountain were rooted in rural area, so it has a strong flavor of localities, which is indicated as follows.

\section{A. The General Cultural Features}

1) Paper-cuts indicate the spiritual culture of the common people: Liupan mountain locates at the south of Ningxia Hui autonomous region, close to the nomad in north and central plain, where is the cradle of Chinese civilization in ancient China. The industrious and brave people expressed their active and optimistic attitude to the hard life by the simple artistic language, so, it is the spiritual culture of the common people.

2) Paper-cuts reflect cultural identity of the woman: It is an indispensable art for beautifying and decorating atmosphere. Creator of the crafts are rural woman, they shouldered the whole heavy burden of their family, but always pursue the beauty in spare time. Paper cuts designs are used in many fork custom, thus it is indication of the special identity for them to inherit the paper-cut culture.

3) Paper-cuts own the plain and simple aesthetic color of the mountain area: Fork paper-cut culture belongs to the field of the mass, it is also a traditional aesthetic culture, the character of original ecology is the core of the paper cut culture, the paper cuts theme are things closely connected with mountain life, [1] for example, flowers, grass, little spider, cat, dogs, zodiac twelve animals paper-cut, etc. their forms are simple but confers a feeling of romantic and beautiful life in the mountain area.

\section{B. The Specific Cultural Features}

1) Paper-cuts design includes people's philosophical idea and belief: It includes the Taoism, Buddhism and Confucianism and it also reflects Heaven stem and Earth branches, a Chinese calendar in ancient China records time and seasonal changes.

2) It is a vehicle for fork custom culture: Paper-cut conveys the traditional fork custom culture by its vivid design. for example, the papercuts are widely used in birthday, funeral and traditional festivals.

3) It reflects the thick local flavor of Liupan mountain culture: It is widely used in decoration for happy atmosphere, so, this is the vitality that keeps the paper-cut in the long run. Since Liupan Mountain is a faraway, rather 
closed in the grand west of China, paper-cuts still keep the original flavor.

\section{EXCHANGES WITH FOREIGN COUNTRIES}

Spreading of paper-cuts is indispensable in the exchanges because Liupan Mountain locates at exactly the Silk Road northern part of the eastern section, by which it was taken to the world earlier than a thousand years.

Nowadays, "Chinese cultural festival" and "paper-cuts festival" are the major platform for spreading of the papercuts in foreign countries. Representatives from foreign countries and China actively participate in the exhibition, some paper-cuts are collected by amateurs or some are sold. The forth plenary held in Yinchuan, Ningxia in 2008. The president of paper cut institution, Kathy Trexel Reed from US says. "The great designs, rat marry his daughter and Love story in Xinjiang are treasures in America paper-cuts museum, we really sense the marvelous dedication of Chinese for the world." [2]

Paper-cuts in Liupan Mountain are popular too. Many foreign tourists like them very much, the collection of Longde county paper-cuts compiled in 1986 were taken to Japan and America. This is a good evidence for the norm "to be national, to be the world". [3]

\section{Problems In TRAnslating PAPER-CUT CUlture}

Paper-cut of Liupan mountain is one of the representative culture in Silk Road culture, Accurately transferring the rich culture in English to foreign friends will create a platform for the rich fork culture, it also benefits the developing and spreading of the culture, which can ensure the connection with the whole world and enhance the recognition of the art culture by foreign friends, thus, the paper-cut art culture can stand in the queue of the fork art culture, the world national culture.

According to the investigation on Liupan mountainous paper-cut, many problems occurred in translation, such as shortage of culture information, even flaw can be founded in the sentence, version of the local culture in Liupan mountainous paper-cut isn't in a systematic way, for instance, Liupan Renjia, a famous fork art brand represent the fork art culture in international exhibition, in translation, four fifths of the paper-cut brochure are occupied by other advertisement. It is a pity that the brochure ignores people's life, belief and aesthetic for the simple and honest art. In fact, the brochure should act as a media for pushing the Liupan mountain culture to the outer world if the full translated text can be afforded.

\section{DIFFICULTIES IN TRANSLATION}

Paper-cut culture is recognized by UNESCO as the intangible cultural heritage. Culture in the traditional fork paper-cut and modern ones contains intangible, sensible and connoted meaning which is difficult to describe in English, therefore, a good translator must fully understand the rural life, experience their custom and have the awareness for the simple fork art beauty, especially farmers' life and contribution to the land. The followings are the cultural loss in translation.

\section{A. Translation Can't Reflect the Meaning Connotated in the Design}

Ordinarily speaking, the connoted meaning is conveyed by way of hyperbole, homophony and metaphor. In appreciating the artistic value of paper-cuts, three steps: gazing, pondering and appreciating should be taken, if one wants to appreciate the real culture and value, the soul of the paper-cut can also reflect in translation, such as, prosperity brought by the dragon and phoenix are figurative language to modify happy and satisfactory marriage, fish and lotus cut in one design is the homophonic for well-off over the years. Mice steal the edible oil means the harmonious life of animal and human being in their shared land. Magpie on the plum trees forecasts the good news and good fortune. So, the implied meanings of the paper-cut design are the focus in translation, if the design are only translated by its denoted meaning, the cultural meaning can't be transmitted.

\section{B. Inappropriate Translation Causes the Misunderstanding of the Culture}

Meaning in a piece of paper-cut is just like a little world, the fork paper-cut culture is also a mirror to the world. The task for translation is to show the value of paper-cut to the world, nevertheless, translation text need to be polished, while we read translation in the brochure, it seems that literal translation is applied, but it's mistranslated words by words, much mistranslation causes obscure in understanding the translated text.

\section{StRategiES SugGeSted In TRANSLATION}

\section{A. Foreignizing Is the Most Favored Strategy in Transferring Culture to Foreigners}

Foreignizing translation lays great emphasis on retaining the cultural flavors of the source language, it also enables the reader to have an alien reading experience, thus developing the reader's awareness of cultural differences [4]. Foreignizing translation is a far better choice than other translation strategies in promoting cultural exchange and mutual understanding between peoples of different cultures easy. In this way, we can better transmit fork paper-cut culture to the foreign culture.

However, weakness of foreignization is that the culturespecific expressions may not be familiar to readers, or the sentences aren't smooth enough for foreigners to read. In this case, literal translation, free translation, transliteral even adding notes can be adopted. Then, the foreigners can feel and sense the true meaning in translation.

1) Example one: Incorrect version: The paper-cut artists by combining realism and romanticism in their artistic expressing, by the means of homophony, metaphor, phonetic loan characters and hyperbole, and using a piece of paper, a scissors and a pair of their clever hands, have 
created lively pictures out of their honest feelings and rich intelligence.

Versions suggested: By applying the ways of romanticism and realism in the window flower, Paper-cut artists create lively pictures with easy and casual grace out of their simple feelings, dexterous hands and rich intelligence. The pictures they cut convey the symbolic meanings in rhetoric effect, such as, homophony, metaphor, hyperbole and phonetic loan characters.

Analysis: from the perspectives of cultural transmitting, beauty and spiritual implication must be conveyed in the translation, Papercut combines the artistic and culture features together, so, the translation must reflect the inner beauty of the art and the outer beauty of the papercut. According to the context in the original translation, it should be transferred "with easy and casual grace" . readers can appreciate and understand the meaning of the papercut art, can imagine the scene the woman who cuts. So, the translator must consider the image, connotative meaning and spiritual beauty of the papercut, and translate it just like people who experiences the art culture in real circumstances.

2) Example two: Incorrect version: The art of paper-cut may be traced back to a period as early as the ancient North and South period of Dynasties. It appeared at the same time of discovery of Chinese paper making and is still prosperous across China.

Versions suggested: Paper-cut art, appeared at the same time as the invention of Chinese paper-making, can be traced back to the period as early as the North and South Dynasties (A.D.386-581), and has been flourishing in China today.

Analysis: Translation can have a long life if target language readers can understand it. [6] paper -making is the symbol for China as a civilized country in ancient times, it was a great dedication for the whole human beings. Foreigners are not strange to paper-making, so, it is easy for readers to know the time while adding the year of the North and South Dynasties (A.D.386-581) in the original sentence. In fact, adding time in the translation can make the information clear, readers and lovers of papercuts can know the cultural more thoroughly by the context, reach the goal for mutual understanding between cultures, so adding specific and necessary information guarantee the translation easy for foreigners.

\section{B. Literal Translation with Explaining Is the Basic Strategy to Be Taken}

There also many Chinese idioms in the paper-cut design, which are applied for celebrations in many circumstances, for example, song he yan nian can be literally translated as pines and cranes-the symbol of longevity, song and he are symbolic for long life, adding explanation can add the implied cultural information; $\mathrm{Xi}$ shang mei shao means pleasures and joyfulness, because $\mathrm{xi}$ is the pronunciation for 'magpie' who stands for the angel bringing happiness, mei stands for 'eyebrow', when one show happiness and smile on his/her face, it can be described as Xi shang Mei shao; kai men jian xi, one can get good news when open the door; long teng hu yue, the version is literal translation, means dragon and tiger leaping, but it symbolizes the strength, braveness and people's aspiration, the vividness of paper cutting pattern imply an atmosphere of joyfulness.

Fork custom is the special color for rural life. It contains many information, and homophony are frequently used, besides literal translation, adding explanation is the number one in translation. Such as, the elder's birthday celebration, 'bat paper-cut' are common favored. Bat stands for bless, since in Chinese, it pronounces bian fu, fu is homophony the of bless.

The Chinese Zodiac paper cutting integrates images of the twelve zodiac signs/twelve animals [5]. the most common one is the combination of snake and rabbit, they face each other with the snake's body surrounding the rabbit, it is the sayings in Chinese pinyin, 'she pan tu, bi ding fu,' most importantly which reflects wealth comes, because 'fu' in Chinese means wealth and richness. 'Shehuo'-A Chinese traditional activity happens in the first month of Chinese Lunar year, but translator have to add the information to explain it, since many performances included in it. "celebrates the new year and actors/actress make up themselves as the role in the Shehuo, with the performance of all kinds of rural dance, for example, dragon light dance, yangko dance and lion dance.

\section{Free Translation in Expressing of Daily Life Paper-cuts}

The versatile farmers can cut the design to show their daily life in many ways. Since the paper-cut concerns things closely connected with the life, so free translation can be taken and made the translation vivid and accurate. for instances: gan ji means going to market; nong jia mang, busy famers; Wu yue duan wu, double Fifth or Chinese traditional dragon boat festival, Xinjiang putao ya ke xi, fantastic grapes come from Xinjiang; pao han chuan means 'running land boats dance'. China has 56 nationalities, many things have their own meanings in different minorities, so, free translation is the best way to express the colorful culture.

\section{CONCLUSION}

Paper-cut culture is one part in the fork art culture; it is not only the local culture, but also the treasure of China. Paper-cut is also the home for people's spirit in rural. In some degree it is coral of human being's wisdom. Chinese traditional culture has the strong influence on the world culture. So, it's the premise to transmit paper-cut culture to the world now and maintain the variety of the world culture. So, we need the understandable and better qualified translation to introduce the special culture to the world. It is clearly proposed in the fifth plenary, 18 sessions that establishing the outstanding heritage system of traditional culture, walking out is the necessary way for blooming of the Chinese culture [6].

\section{REFERENCES}

[1] Hu Xishan, "The fork paper-cut in Xihaigu," Yang Guang press, Yinchuan, 2015.12, p13 
[2] Tao Yufang, "Collection of International Papercut", Ningxia people's Press, 2008.8, p7

[3] Sima Faliang, "Paper carving and paper cutting,", Ancient books publishing house of China, 2015.7, p113

[4] Lian Shuneng, "A coursebook on English-Chinese Translation," Higher education press, 2006.9, p313

[5] Xu Gang, "The twelve zodiac signs", Huangshan press, 2013.5, p 125

[6] Li Jianghui, "The urgent scientific need for protection of cultural heritage", Journal of the Chinese People's political consultative conference, 2010.11.12. 